\title{
Monitoring changes at work: cross-cultural difference in employees' evaluation
}

\author{
Alena Fedorova ${ }^{1, *}$, Zuzana Dvorakova ${ }^{2}$, Ilze Kacane ${ }^{3}$, Huseyin $\mathrm{Atas}^{4}$, and Valeriya \\ Badambayeva $^{5}$ \\ ${ }^{1}$ Ural Federal University, Department of the HR Management and Psychology, Mira 19, 620002 \\ Yekaterinburg, Russian Federation \\ ${ }^{2}$ University of Chemistry and Technology, Prague, School of Business, Technická 5, 16628 Praha 6 \\ - Dejvice, Czech Republic \\ ${ }^{3}$ Daugavpils University, Prague, Centre of Cultural Research, Institute of Humanities and Social \\ Sciences, Vienibas 13, Daugavpils, Latvia LV-5401, Latvia \\ ${ }^{4}$ Adiyaman University, Department of Marketing and Advertising, Vocational School of Social \\ Sciences, Adiyaman 02000, Turkey \\ ${ }^{5}$ Turan University, Language Training Centre, Satpaeva, 16A, Almaty, 050013, Kazakhstan
}

\begin{abstract}
Research background: Globalization and digitalization of society are leading to fundamental alterations in the labour sphere. Global trends and turbulent times are changing the work environment, stipulating the emergence of new forms of labour relations and employment models. Thinking on the on-going transformation processes requires a monitoring study of new phenomena, as well as the creation of a knowledge system about the directions and prospects of human resources management and labour relations development.

Purpose of the article: The article presents the interim results of the current monitoring changes in labour relations conducted by the international research team members. The empirical data obtained are considered in the context of the social and cultural features of respondents from different countries that contributes to a deeper understanding of the phenomena under study.

Methods: In 2020, the authors carried out a sociological survey involving employees of enterprises operating in various sectors of the economy in the Russian Federation, the Czech Republic, Latvia, Turkey and Kazakhstan. The total number of respondents formed by random sampling is amounted to 1138 people. For the purpose of a comprehensive typology of the surveyed workers from different countries, a cluster analysis of the collected data was carried out.

Findings \& Value added: A comparative analysis of the sociological survey results reflects the trends in work transformation and labour relations that have developed under the Covid-19 pandemic. Cross-cultural analysis reveals the impact of social and cultural factors on respondents' assessment and companies' human resource management practices.
\end{abstract}

\footnotetext{
* Corresponding author: dekan 2002@mail.ru
} 
Keywords: cross-country study; labour relations; human resource management practices; comparative analysis; cluster analysis

JEL Classification: F66; J53; M54

\section{Introduction}

Sociocultural factors include a variety of informal institutions associated with values and behaviours shared by a particular society and slowly changing over time. Under the factor of sociocultural diversity in the presented study, the authors take the definition of this concept as "the relative number and composition of population groups distinguished according to certain characteristics" (Kolosova, 2012). Sociocultural factors influence social and economic processes both at the micro level (i.e., within one enterprise) and at the meso- and macrolevels (the region and the country as a whole).

The sociocultural aspect implies such features characteristic of a certain community that can be measured in a certain way and used for comparison with the sociocultural aspect of another community (Kolosova, 2012). Some researchers attribute power distance, individualism, uncertainty avoidance, temporal orientation, etc. to such sociocultural features (Hofstede et al., 2010). Other researchers distinguish such sociocultural peculiarities as a person's attitude to nature, orientation in time, orientation toward the activity of relationships between people, orientation in space, etc. (Lane and DiStefano, 1988). Song and Parry (1997) examine the sociocultural differences between R\&D and marketing managers across five dimensions: time orientation, bureaucratic orientation, career orientation, tolerance for ambiguity, and preference for high-risk and high-return projects.

The growing diversity of the workforce in terms of age, gender, ethnicity, various needs, motivations, preferences (Gubler et al., 2014), differences in values, goals, motivation (Liao et al., 2009) and sociocultural characteristics require the adoption of differentiated personnel decisions. The effectiveness of personnel management practices that resonate with employees today also depends on the sociocultural features of human resources.

The sociocultural specificity of human resources imposes associated restrictions on the development of labour relations and companies' human resource management. For example, the results of studies by Ayoko et al. (2021) expand the literature on sociocultural adaptation and further develop the concept of cultural intelligence in relation to human resource management. In the context of the cultural fit model, Keleş and Aycan (2011) examined the relationship of management values and assumptions with performance management practice in order to understand the internal cultural variability in the implementation of management functions. They found that managers were more likely to apply methods that were consistent with their values and assumptions. A new framework for human resource management practice is proposed by Putnik et al. (2020): a pyramid of intersecting areas of the work and home interface (WHI), which includes the cultural context and other important aspects of the WHI.

The sociocultural characteristics of the personnel are the context within which the company operates. With effective consideration of the sociocultural features of human behaviour in different countries, it is possible to significantly increase the efficiency of human resource management (Hofstede et al., 2010). Elenkov and Manev (2005) found that the sociocultural context directly affects leadership and regulates its relationship with organizational innovation. Chavez and Weisinger (2008) presented a strategic approach to organizational diversity designed to create a "culture of diversity" that emphasizes attitudes and cultural transformation to capitalize on the unique perspectives of a diverse workforce. 
Banerjee-Batist et al. (2019) identified sociocultural factors (gender, ethnicity, culture, and age) and individual difference variables that play into the development of mentoring relationships. Erez (1986) investigated the correspondence between goal-setting strategies for group participation, participation through representation and non-participation, and the sociocultural values of the work environment.

Sociocultural attitudes can work both to speed up economic development and to slow it down (Kolosova, 2012). With the effective use of sociocultural attitudes, they become a competitive advantage of the company. It should be noted here that the changes taking place today in the labour sphere have high-speed dynamics and require personal steadiness from the employee. To solve the problem of sustainable development of the company's human potential in a rapidly changing environment, it is necessary to actualize such personnel abilities as awareness, feeling, reflection (Volkov, 2017), determined by the sociocultural characteristics of employees.

Drawing on the sociocultural aspect literature and research on sociocultural factors, the authors develop a sociocultural approach to human resource management. In the process of the presented study, the authors carried out a comparative analysis of the sociocultural characteristics of the interviewed workers in a number of countries with different models of social and economic development, identified on the basis of cluster analysis of empirical data from a sociological survey.

\section{Methods}

The results of a monitoring study presented in the article were obtained by conducting a sociological survey of hired workers in different economy sectors in January-February 2021. The general population of respondents was formed by attracting employees from Russia, the Czech Republic, Turkey and Kazakhstan to the online survey and amounted to 1,138 people, of which the majority are those working: at Russian enterprises -537 people (47.2\%), 203 people (17.8\%) - in the Czech Republic, 80 people (7.0\%) - in Latvia, 166 people $(14.6 \%)$ - Turkish and 152 people $(13.4 \%)$ - Kazakh workers. Due to the limited resources required for conducting a sociological survey, a spontaneous sample was obtained in each of these countries, implying a survey on the principle of "any available respondent". The disadvantage of spontaneous sampling is weak representativeness due to the discrepancy between some of the characteristics of the sample population and the characteristics of the general population. Therefore, this study is complemented by methods of qualitative analysis. For example, in 2020, the authors tested the algorithm and procedures for multivariate analysis in order to identify the features and the most significant social pollution factors of labour relations in the countries under study.

The cluster analysis of empirical data was carried out with the aim of typologizing on the basis of the socio-cultural aspect of the surveyed workers from separate countries. When interpreting the results obtained, it was considered that the respondents' answers to the questionnaire are ambivalent. On the one hand, they are associated with the objective situation prevailing at the companies, as well as the processes taking place in the industry, the country of residence. On the other hand, the perception and attitude to these conditions and processes are subjective: some employees react sharply to changes, others believe that they will not be personally affected by these changes, or do not notice any changes at all.

In the presented sociological study, qualitative indicators with a single and multiple choice are mainly used, while for cluster analysis, quantitative or binary indicators with a single choice are required. To solve this problem, the initial variables (questions) were transformed based on the specifics of their measurement:

- tabular questions in the frame of more specific ones - "What is the source of your anxiety and negative emotions at your current job?", "What actions do you have to take to 
keep your job?" and "How does your work affect your physical and psychological health?" - contain answer options with the same ordinal measurement scale "never", "rarely", "often", "constantly". Based on these questions, the conditional indices "General index of concern about the current work", "General index of the negative impact of work on health and well-being" and "General index of the need to take action to save the workplace" were calculated, measured from 0 (the employee for all questions answers "never", for example, he/she never worried about any of the reasons listed in the table related to his/her current job) to 1 (for example, the employee is constantly forced to worry about all the reasons related to his/her current job). The resulting general indices have a distribution with a very strong skew: the majority of respondents rarely worry about their current job, work rarely affects their health and well-being, and employees rarely have to take various actions to keep their jobs;

- multiple choice questions containing the dominant answer (the only answer chosen by the majority of those surveyed), such as "What managerial decisions have adversely affected your well-being in the past year?" and "What cases of agreements infringement with the employer did you have to face over the past year?" are brought to a binary form according to the principle "the dominant or other value is chosen". At the same time, the dominant answer in both cases was "There were no such cases";

- multiple choice questions, such as "What threats to your future exist at your current job?" and "What changes in the personnel policy of your organization have occurred over the last year?", do not have a pronounced dominant meaning and could not be reduced to a binary form. For this purpose, a preliminary cluster analysis was carried out here, which made it possible to identify popular non-overlapping combinations of answers and to form enlarged clusters used as binary parameters in the subsequent analysis.

Thus, 7 variables are prepared for the final cluster analysis, of which 3 variables are presented quantitatively (in the range from 0 to 1), 2 variables are binarized variables and 2 variables are clustered variables (each cluster, in turn, is presented in binary form). The analysis was carried out in the program for processing sociological and marketing data "Vortex 10". At the same time, since all the variables were measured either from 0 to 1 , or were binary ( 0 - the answer was not selected, 1 - the answer was selected), preliminary standardization was not performed. Simple Euclidean distance was used as a measure of distance.

\section{Results and Discussion}

Judging by the silhouette measure of connectivity and separation of clusters (Baier et al., $2005)$, the optimal solution is 2 clusters, the first of which $(54.8 \%)$ is relatively prosperous: workers in this cluster have low indices of concern about their current work, the negative impact of work on physical health and well-being, the need for take various actions to keep their jobs, they did not encounter a violation of agreements by the employer, did not face unfavourable managerial decisions, for most of them there are no threats about their current work or unfavourable human resource management practices. The second cluster $(45.2 \%)$ consists of workers who have faced certain problems at work and have high indices of concern. However, this binary solution seems to be too obvious, therefore, the authors adopted a solution of 7 clusters as the optimal one.

The first cluster "No changes in the level of well-being at work" (24.80\%) includes respondents with the lowest indices of anxiety about their current job, the negative impact of work on health and well-being, and the need to take various actions to keep their jobs (hereinafter - indices of concern/anxiety). Over the past year, the employees of this cluster have not faced any violations of agreements by employers, as well as with decisions of the management, which negatively affected their well-being. They do not feel any threats in 
their current work, and few of them have faced negative changes in personnel policy over the past year, with the exception of the forced temporary transition to a remote work mode.

The second cluster "High objective probability of a decrease in the level of well-being at work" (5.87\%) includes respondents who have faced unfavourable management decisions and violations of agreements by employers. In their organizations, the staff is transferred to a remote work, there are frequent reductions in the employees' number, the attraction of seasonal workers and the hiring of new personnel only on short-term employment contracts. In this regard, these respondents have relatively high indices of anxiety: their negative subjective feelings are justified by objective factors.

The third cluster "Reasonably high level of concern about well-being at work" (20.44\%) is made up of those respondents who have encountered agreements infringement by employers, unfavourable managerial decisions, staff reductions and other unfavourable personnel decisions are made in their companies. Representatives of this cluster are characterized by the highest indices of concern. The key difference from the second cluster is that representatives of this cluster note a wide variety of existing threats.

The fourth cluster "Decrease in the level of well-being due to the transition to teleworking mode" $(12.80 \%)$ includes the workers, in respect of whom there were no violations of agreements on the part of employers and unfavourable managerial decisions, but they faced various threats to their future on current work, and a large share of them $(43 \%)$ work in companies that are forced to take staff to remote work. The indices of anxiety are lower than the average for the array.

The fifth cluster "Weakly expressed personnel decisions unfavourable for employees" $(12.89 \%)$ are those respondents in respect of whom, over the last year, there were unfavourable decisions of the management of their companies, but there was no violation of agreements on the part of employers. As a result, their subjective indices of anxiety are lower than in the whole array.

The sixth cluster "High level of concern in connection with agreements' infringement by employers" (13.07\%) consists of those employees, in respect of whom there were no negative decisions of the management over the past year, but there were violations by employers of their obligations to employees. Representatives of this cluster have significantly higher subjective indices of anxiety than the representatives of the fifth cluster.

The seventh cluster "Unreasonably high level of concern about well-being at work" $(10.13 \%)$ consists of respondents for whom over the past year there were no unfavourable decisions of the management, there were no violations of agreements on the part of employers, there were no adverse changes in the personnel policy of the enterprise, however, they feel various threats to their future at their current job, in connection with which their subjective indices are twice as high as those of the employees of the first "prosperous" cluster. The workers representing this cluster seem to be the most impressionable, since there are few objective grounds for their concern.

Objective characteristics of surveyed employees included in each of the clusters are presented in Table 1.

Table 1. Structure of workers surveyed in different clusters by country, $\%$ of the respondents' number in each country

\begin{tabular}{|c|c|c|c|c|c|c|}
\hline \multirow[b]{2}{*}{ Clusters } & \multicolumn{5}{|c|}{ Countries under study } & \multirow[b]{2}{*}{ Total } \\
\hline & $\begin{array}{c}\text { Russian } \\
\text { Federation }\end{array}$ & Kazakhstan & Turkey & $\begin{array}{c}\text { Czech } \\
\text { Republic }\end{array}$ & Latvia & \\
\hline $\begin{array}{l}\text { 1. "No changes in the level of } \\
\text { well-being at work" }\end{array}$ & 32.58 & 24.50 & 14.91 & 16.26 & 15.19 & 24.80 \\
\hline $\begin{array}{l}\text { 2. "High objective probability } \\
\text { of a decrease in the level of } \\
\text { well-being at work" }\end{array}$ & 3.20 & 9.27 & 8.70 & 8.87 & 3.80 & 5.87 \\
\hline
\end{tabular}




\begin{tabular}{|l|c|c|c|c|c|c|}
\hline $\begin{array}{l}\text { 3. "Reasonably high level of } \\
\text { concern about well-being at } \\
\text { work" }\end{array}$ & 20.53 & 23.18 & 22.36 & 18.72 & 15.19 & 20.44 \\
\hline $\begin{array}{l}\text { 4. "Decrease in the level of } \\
\text { well-being due to the } \\
\text { transition to teleworking } \\
\text { mode" }\end{array}$ & 12.05 & 5.96 & 8.07 & 22.17 & 16.46 & 12.80 \\
\hline $\begin{array}{l}\text { 5. "Weakly expressed } \\
\text { personnel decisions } \\
\text { unfavorable for employees" }\end{array}$ & 9.42 & 10.60 & 16.15 & 20.20 & 15.19 & 12.89 \\
\hline $\begin{array}{l}\text { 6. "High level of concern in } \\
\text { connection with } \\
\text { agreements' infringement } \\
\text { by employers" }\end{array}$ & 13.37 & 17.22 & 14.91 & 7.88 & 12.66 & 13.07 \\
\hline $\begin{array}{l}\text { 7. "Unreasonably high level of } \\
\text { concern about well-being at } \\
\text { work" }\end{array}$ & 8.85 & 9.27 & 14.91 & 5.91 & 21.52 & 10.13 \\
\hline
\end{tabular}

* Cramer V coefficient [0..1]: 0.156, Probability of error (significance): 0.000

Source: Authors' elaboration

The structure of representatives of the selected clusters differs in the studied countries:

- employees of the first ("prosperous") cluster are most represented among Russian and Kazakh respondents $(32.58 \%$ and $24.5 \%$ of all respondents in Russia and Kazakhstan, respectively);

- representatives of the second cluster, who have objective grounds for fear of losing their jobs, are most often found in Kazakhstan $(9.27 \%)$, Turkey $(8.70 \%)$ and the Czech Republic $(8.87 \%)$ and much less often in Russia (3.20\%) and Latvia (3.80\%);

- representatives of the third cluster, in whom adverse decisions of the management had a noticeable impact on health and well-being, were approximately equally distributed in all countries, but they slightly prevail in Kazakhstan (23.18\%) and Turkey (22.36\%), their number is somewhat smaller in the Czech Republic (18.72\%) and Latvia (16.46\%);

- representatives of the fourth cluster, indicating the presence of a wide range of threats to their future in their current job, are less common in Kazakhstan (5.96\%) and Turkey (8.07\%), much more often in the Czech Republic (22.17\%) and Latvia (16.46\%);

- employees of the fifth cluster, noting unfavourable decisions of the management, but having no significant consequences for well-being in the workplace, are significantly more often represented in the Czech Republic (20.20\%) and twice less often in Russia $(9.42 \%)$ and Kazakhstan (10.60\%);

- employees of the sixth cluster, experiencing serious anxiety in connection with violations of agreements by employers, are more common in Kazakhstan (17.22\%) and less often in the Czech Republic (7.88\%);

- representatives of the seventh cluster, experiencing unreasonable anxiety about changes in their current job, are more common in Latvia $(21.52 \%)$ and less often in the Czech Republic (5.91\%), Russia (8.85\%) and Kazakhstan (9.27\%).

Analysis of the respondents' characteristics revealed that the most significant feature that differentiates workers by cluster is the gender. There are more representatives of the "prosperous" cluster among men (30.63\%) than among women (20.59\%). Among women, in turn, representatives of the fifth cluster are much more common $(17.63 \%$ of women versus $6.67 \%$ of men).

For women, the second most important parameter was belonging to a certain personnel category. Most of the representatives of the "prosperous" cluster are found among female manual workers and leaders (29\%). While among women working as service personnel, the representatives of the "prosperous" cluster are only $10 \%$ and noticeably higher, the share of 
the representatives of the fifth cluster (24\%). The sphere of activity of the organization also plays a significant role: among those working in the IT sphere, the share of women in the first cluster is $47 \%$, in the sphere of production $-36 \%$, in the civil service $-30 \%$, while in the spheres of energy, construction and real estate, marketing and PR representatives of the "prosperous" cluster make up less than $10 \%$. In these areas, there are noticeably more representatives of the third cluster (35-42\%).

For men, parallel employment turned out to be an important factor in getting into one cluster or another. If a male worker has several sources of income (combines several jobs), then he is less likely to fall into the "prosperous" cluster $(20 \%)$ and less often to the third cluster (35\%). If the salary at the current job is the only source of income (there is no need for part-time jobs), then the share of such workers in the "prosperous" cluster increases to $37 \%$. The second important criterion for men, as well as for women, is the industry. Representatives of the "prosperous" cluster are most often found in the IT sector $(55.55 \%)$ and in production (37.97\%), and least often in marketing and PR (9.09\%) and in the civil service $(14.29 \%)$. Representatives of the second cluster among men are concentrated in health care $(26.67 \%)$ and public service $(14.29 \%)$. Representatives of the third cluster are more common in the field of advertising and PR (36.36\%), there are also many representatives of the seventh cluster $(45.45 \%)$.

The features of workers interviewed at enterprises in various countries are discussed below.

The analysis shows that a third of the Russian respondents were concentrated in the first "prosperous" cluster. The smallest number of representatives from Russia is in the second "most disadvantaged" cluster. At the same time, the third cluster is more represented than in Latvia and the Czech Republic. There were also fewer representatives of the fifth cluster in Russia. These results are due to the following characteristics of the answers of Russian respondents in comparison with the interviewed workers from other countries under study:

- agreements violation by employers over the past year were noted by $37.1 \%$ of surveyed workers from Russia, which is significantly less than in Kazakhstan (49.67\%) and Turkey (46.39\%) and slightly more than in Latvia (31.65\%) and the Czech Republic (35.47\%). The main agreement infringements in Russia include an increase in the volume of work without a wage increase $(21.3 \%)$ and non-payment of the promised remuneration $(11.11 \%)$;

- a third of the surveyed Russian workers (33.27\%) faced unfavourable decisions of the management, which is significantly less than in other countries (excluding the Czech Republic with $34.18 \%$ ). Most often, Russian employees noted a decrease in the amount of remuneration $(10.9 \%)$;

- two-thirds (67.3\%) of Russians surveyed faced changes in personnel policy over the past year. Most often, Russians note the transfer of a part of employees to a distance work (27.63\%), as well as reductions and hiring new employees for a short period (23.12\%);

- Russian respondents were less likely than surveyed workers in other countries under study to face threats to their future at their current job, they mainly note a decrease in the level of job satisfaction $(26.13 \%)$, a deterioration in physical health at the workplace $(19.55 \%)$, a decrease in the amount of monetary remuneration $(18.98 \%)$;

- Russian workers have the lowest overall employee anxiety index about their current job (0.189, for comparison in the Czech Republic -0.217 , in Turkey -0.359 ), they are less worried about the need to work remotely (anxiety index - 0.122), lack of a personal workplace (anxiety index - 0.128);

- the total index of the negative impact of work on health and well-being in Russia was in second place (0.205), according to this indicator, Russia is noticeably inferior to the Czech Republic (0.129). Russian respondents are less likely to overeat because of problems at work, they have to go to work less often in a state of illness. At the same time, in 
comparison with the interviewed workers from the Czech Republic, Russian respondents are much more likely to experience a deterioration in well-being at the workplace, suffer from headaches, feel tired and fatigued;

- the total index of the need to take action to save a job in Russia (0.146) was about the same as in the Czech Republic (0.145) and Latvia (0.146), but significantly lower than in Turkey (0.272) and Kazakhstan (0.186). Russian workers are less likely to have to improve their qualifications at their own expense $(0.135)$ and participate in unfair competition among colleagues (0.099). More often than the interviewed workers in the Czech Republic and Latvia, Russians have to work overtime $(0.119)$ and carry out hard-hitting managerial commands (0.082).

The key indicator that differentiates cluster affiliation in Russia was not gender, but the need for additional sources of income. Those for whom the salary at the main place of work is the only source of income is much more likely to fall into the "prosperous" cluster (40\%) than those who have several labour sources of income (15\%). The latter are more likely than others to find themselves in a relatively disadvantaged cluster (here there are very high subjective indices due to unfavourable decisions of the management) (37\%), especially if these are male workers (47\%), who also more often than others find themselves in the most "non-prosperous" second cluster (8\%).

Despite the good performance in general, Czech respondents are relatively rarely included in the first "prosperous" cluster $(16 \%)$. Among the surveyed employees of Czech companies, representatives of the fourth $(22.17 \%)$ and fifth $(20.2 \%)$ clusters can be found more often than others. Clustering of the surveyed Czech workers depends most of all on the level of their education. Employees who do not have a master's degree are less likely to fall into the first "prosperous" cluster (5\%), more often into the second or third (most "disadvantaged") $-11 \%$ and $26 \%$, respectively. As for workers with a master's degree, their share in the "prosperous" cluster is much higher - $29 \%$. At the same time, among the latter, more than a third (38\%) of those who have income from several sources. Those who have a salary at their main place of work as their main source of income are more likely to fall into the fifth cluster (34\%).

The surveyed workers from Turkey are more likely than others fall into the third cluster $(22.36 \%)$ and less often to the first "prosperous" cluster $(14.91 \%)$. The key basis for the differentiation of Turkish employees by cluster is their belonging to a national minority. Only $2 \%$ of representatives of national minorities are in the first "prosperous" cluster, $12 \%$ find themselves in the second most "non-prosperous" cluster and $38 \%$ - in the third cluster. For the national majority, the industry is also important: trade, education, finance and public service are more "prosperous" than others.

For workers surveyed in Kazakhstan, a dual situation is characteristic: a quarter of the respondents are in both the first "prosperous" cluster (24.5\%) and in the second and third "non-prosperous" clusters $(9.27 \%$ and $23.18 \%$, respectively). More than in other studied countries, representatives of the sixth cluster are found in Kazakhstan (17.22\%). The main factor in the differentiation of Kazakh employees is the sector of enterprise activity: the most "prosperous" are education and culture, and much less - trade, construction, real estate, health care, marketing, advertising, PR, civil service.

In Latvia, it was not possible to identify objective factors of falling into a particular cluster due to the small amount of collected data. One can only note the high proportion of respondents in the seventh cluster $(22.52 \%)$ and the relatively small proportion of workers who fell into both the first cluster $(1.19 \%)$ and the "non-prosperous" second $(3.8 \%)$ and third $(15.19 \%)$ clusters.

Generalizing of the cluster analysis results of the aggregate of respondents' answers obtained during the survey allows the authors to propose a classification of sociocultural 
factors that affect the level of workers well-being in the labour sphere, considering national peculiarities (Table 2).

Table 2. Classification of sociocultural factors affecting the level of employees' well-being at work, taking into account national peculiarities

\begin{tabular}{|l|l|c|c|}
\hline \multirow{2}{*}{$\begin{array}{c}\text { Countries } \\
\text { under study }\end{array}$} & \multirow{2}{*}{$\begin{array}{c}\text { The main factors of the } \\
\text { respondents' cluster structure }\end{array}$} & \multicolumn{2}{c|}{ Clusters } \\
\cline { 3 - 4 } & "prosperous" & "non-prosperous" \\
\hline All countries & Gender & Men & Women \\
\hline $\begin{array}{l}\text { Russian } \\
\text { Federation }\end{array}$ & $\begin{array}{l}\text { Number of sources of labour } \\
\text { income }\end{array}$ & $\begin{array}{c}\text { Salary/wage only at the } \\
\text { main place of work }\end{array}$ & $\begin{array}{c}\text { Several sources of } \\
\text { labour income }\end{array}$ \\
\hline $\begin{array}{l}\text { Czech } \\
\text { Republic }\end{array}$ & Level of education & Master's degree & $\begin{array}{c}\text { Bachelor's degree and } \\
\text { below }\end{array}$ \\
\hline Turkey & $\begin{array}{l}\text { Membership in a national } \\
\text { minority/majority }\end{array}$ & National majority & National minority \\
\hline Kazakhstan & $\begin{array}{l}\text { Industry affiliation of the labour } \\
\text { application sphere }\end{array}$ & Education and culture & $\begin{array}{c}\text { Trade, construction, } \\
\text { real estate, healthcare, } \\
\text { marketing, public } \\
\text { service }\end{array}$ \\
\hline
\end{tabular}

Source: Authors' elaboration

\section{Conclusion}

Designing global transformations in a company, it is necessary to simultaneously decide: 1) to ensure acceptance of the transformations by personnel in the medium term, one should rely on the current perception and behavioural attitudes of employees, 2) to move to the target trajectory of development in the long term, a system of management measures should be envisaged that contribute to the desired value shift. It is no doubt that effective managerial decisions on corporate human resource management today require considering the sociocultural characteristics of personnel. The actualization of certain sociocultural aspects depends on the goals set.

Among the main limitations of the research presented in the article, one should mention the heterogeneity and insufficient amount of empirical data obtained. In this case, cluster analysis as a method of multifactorial explanation of phenomena, processes, behavior, accompanied by their multidimensional classification, makes it possible to determine the similarities and differences necessary to identify the fundamental elements in the aggregate of these data. Interpreting a cluster structure, which in many cases starts with determining the number of clusters, is a creative challenge and is often used when it is necessary to organize a complex set of data before developing hypotheses for causal modeling, as well as when creating descriptive classifications and typologies. Based on the results of cluster analysis of data an inter-country sociological study, the authors proposed a classification of sociocultural factors that affect the level of employees' well-being at work, taking into consideration national characteristics.

\section{Acknowledgement}

This work was supported by Russian Foundation for Basic Research (RFBR) under Grant № 19-010-00705 'Development of tools for assessing the impact of social pollution of labour relations on the employees' wellbeing in a digital economy'. 


\section{References}

1. Ayoko, O. B., Zhang Y., \& Nicoli, J. (2021). Conflict and socio-cultural adaptation: the mediating and moderating role of conflict communication behaviors and cultural intelligence. The International Journal of Human Resource Management.

2. Baier, D., Decker, R., \& Schmidt-Thieme, B. (Eds.). (2005). Data Analysis and Decision Support. Springer-Verlag Berlin Heidelberg.

3. Banerjee-Batist, R.; Reio, T. G., \& Rocco, T. S. (2019). Mentoring Functions and Outcomes: An Integrative Literature Review of Sociocultural Factors and Individual Differences. Human Resource Development Review, 18(1), 114-162.

4. Chavez, C. I., \& Weisinger, J. Y. (2008). Beyond diversity training: A social infusion for cultural inclusion. Human Resource Management, 47(2), 331-350.

5. Elenkov, D. S., \& Manev, I. M. (2005). Top management leadership and influence on innovation: The role of sociocultural context. Journal of Management, 31(3), 381402.

6. Erez, M. (1986). The Congruence of Goal-Setting Strategies with Socio-Cultural Values and its Effect on Performance. Journal of Management, 12(4), 585-592.

7. Gubler, M., Arnold, J., \& Coombs, C. (2014). Reassessing the protean career concept: Empirical findings, conceptual components, and measurement. Journal of Organizational Behavior, 35(S1), S23- S40.

8. Hofstede, G., Hofstede, G. J., \& Minkov, M. (2010). Cultures and organizations: software of mind (3rd ed.). McGraw-Hill Education.

9. Keleş, S., \& Aycan, Z. (2011). The relationship of managerial values and assumptions with performance management in Turkey: understanding within culture variability. The International Journal of Human Resource Management, 22(15), 3080-3096.

10. Kolosova, R. P. (2012). Social'no-trudovye otnoshenija: sociokul'turnaja dominanta. Sociologija $i$ obshhestvo: global'nye vyzovy i regional'noe razvitie. Materialy IV Ocherednogo Vserossijskogo sociologicheskogo kongressa. Moskva, 8770-9774.

11. Lane, H. W., \& DiStefano, J. J. (1988). International management behavior: from policy to practice. Nelson Canada.

12. Liao, H., Toya, K., Lepak, D. P., \& Hong, Y. (2009). Do they see eye to eye? Management and employee perspectives of high-performance work systems and influence processes on service quality. Journal of Applied Psychology, 94(2), 371-391.

13. Putnik, K., Houkes, I., Jansen, N., Nijhuis, F., \& Kant I. (2020). Work-home interface in a cross-cultural context: a framework for future research and practice. The International Journal of Human Resource Management, 31(13), 1645-1662.

14. Song, X. M., \& Parry, M. E. (1997). Teamwork barriers in Japanese high-technology firms: The sociocultural differences between R\&D and marketing managers. Journal of Product Innovation Management, 14(5), 356-367.

15. Volkov, I. E. (2017). Sociokul'turna real'nost' - artefakt menjajushhegosja mira. Izvestija vuzov. Serija “Gumanitarnye nauki”, 8(4), 294-297. 